\title{
An Analysis of the Impact of Climate Change on the Korean Onion Market*
}

\author{
Ho-Seung BAEK**, In-Seck KIM ***
}

Received: February 14, 2020 Revised: February 28, 2020 Accepted: March 05, 2020.

\begin{abstract}
Purpose: Agriculture, which is heavily influenced by climate conditions, is one of the industries most affected by climate change. In this respect, various studies on the impact of climate change on the agricultural market have been conducted. Since climate change is a long-term phenomenon for more than a decade, long-term projections of agricultural prices as well as climate variables are needed to properly analyze the impact of climate change on the agricultural market. However, these long-term price projections are often major constraints on studies of climate changes. The purpose of this study is to analyze the impacts of climate changes on the Korean onion market using ex-post analysis approach in order to avoid the difficulties of long-term price projections. Research design, data and methodology: This study develops an annual dynamic partial equilibrium model of Korean onion market. The behavioral equations of the model were estimated by OLS based on the annual data from 1988 to 2018. The modelling system is first simulated to have actual onion market conditions from 2014 to 2018 as a baseline and then compared it to the scenario assuming the climatic conditions under RCP8.5 over the same period. Scenario analyses were simulated by both comparative static and dynamic approach to evaluate the differences between the two approaches. Results: According to the empirical results, if the climate conditions under RCP8.5 were applied from 2014 to 2018, the yield of onion would increase by about $4 \%$, and the price of onion would decrease from $3.7 \%$ to $17.4 \%$. In addition, the average price fluctuation rate over the five years under RCP8.5 climate conditions is $56 \%$, which is more volatile than $46 \%$ under actual climate conditions. Empirical results also show that the price decreases have been alleviated in dynamic model compared with comparative static model. Conclusions: Empirical results show that climate change is expected to increase onion yields and reduce onion prices. Therefore, the appropriate countermeasures against climate change in Korean onion market should be found in the stabilization of supply and demand for price stabilization rather than technical aspects such as the development of new varieties to increase productivity.
\end{abstract}

Keywords : Climate change, Onion, Ex-post analysis, Dynamic partial equilibrium model

JEL Classification Code: C51, C53, Q11, Q18

\section{1. 서론}

지구온난화로 대표되는 전 세계적 기후변화 현상과 그 위험성에 대한 과학적 증명이 쌓여가면서, 이제 기후변화에 대한 입장과 대응방안은 국가와 정치집단의 성격을 규명할 정도로 사회·경제적으로 중요한 이슈가 되었다.

*This paper was modified and developed from the MS thesis of the first author

${ }^{* \star}$ First Author, Researcher, Korea Rural Economic Institute, Korea. ${ }^{* * *}$ Corresponding Author, Associate Professor, Department of Agricultural Economics, Chonnam National University, Korea, Email: i.kim@jnu.ac.kr

๑) Copyright: Korean Distribution Science Association (KODISA)

This is an Open Access article distributed under the terms of the Creative Commons Attribution NonCommercial License (https://creativecommons.org/licenses/by-nc/4.0/) which permits unrestricted noncommercial use, distribution, and reproduction in any medium, provided the original work is properly cited.
기후변화 현상과 원인 그리고 잠재적인 미래 위험에 대한 과학, 기술, 사회 경제적 포괄적 평가를 정리한 기후 변화에 관한 정부간 협의체(IPCC: Intergovemmental Panel on Climate Change) 5 차 평가보고서(AR5: the Fiffh Assessment Report)들 (IPCC, 2013; IPCC, 2014a; IPCC, 2014b)에 의하면 1950 년대 이래로 목격하고 있는 기후변화 현상은 명백한 현실이며 수천 년간 전례가 없었던 것으로 그 주요 원인은 인간 활동에서 찾을 수 있다. 또한 IPCC 보고서들에 의하면 기후시스템에 대한 인간의 영향은 분명한 사실이고 그 정도가 점점 커져가고 있다.

모든 산업들이 거의 예외 없이 기후변화에 영향을 받지만, 기온과 강수량, 일조량 등 기후조건에 큰 영향을 받는 농산업은 기후변화에 가장 큰 영향을 받는 산업 중 하나라 할 수 있다. 기후변화는 농업생산성에 영향을 미치고 이는 식량 가격의 변동성을 증가시키는 요인으로 작용하여 궁극적으로 식량 접근, 이용 및 가격 안정성을 포함한 식량 안보의 모든 측면에 영향을 미친다(Porteretal,,2014). 
이러한 측면에서 기후변화가 농업에 미치는 영향에 대해 다양한 경제학적 분석이 진행되어 왔다. 이들 연구의 분석범위는 전세계(Bosello et al., 2012), 국가(Georgopoulou et al, 2017; Amamoua et al. 2018), 지역(Abdul-Razak and Kruse, 2017; Afroz et al., 2019)으로 다르고, 분석 방법 또한 비용편익 분석(Watkiss et al, 2015), 최적화 모형(Chang 2002), 일반균형 모형(Mushtaq, 2018) 부분균형 모형(Frank et al., 2014) 등 개별적인 차이점이 있지만 대부분의 연구가 미래시점의 기후변화와 관련된 사전분석(ex-ante analysis)이라는 공통점이 있다.

기후변화와 관련된 연구는 대부분이 10 년 이상의 장기예측이고, 100 년에 가까운 세기말의 상태를 전망 분석하는 경우도 많다(Porter et al, 2014; Smith P. et al., 2014). 이에 따라 기후변화가 농산물시장에 미치는 영향에 대한 사전분석들은 기후변화시나리오와 관련된 기후변수들의 장기 전망뿐만 아니라 동일한 기간의 농산물 가격에 대한 장기 전망을 필요로 한다.

장기 농산물 가격전망은 기후변수 외에 농산물 수급에 영향을 미치는 다양한 요인들의 장기전망치가 필요하다. 따라서 기후변화가 농산물 시장에 미치는 영향에 대한 분석은, 많은 경우 장기 가격전망 과정이 분석의 한계점으로 작용하며, 동시에 분석결과의 신뢰성에 의문을 남기는 요소가 된다.

본 연구는 이러한 선행연구들의 한계점을 극복하기 위하여, 기후변화가 농산물 시장에 미치는 영향을 현재시점에서 미래를 전망하는 사전분석(ex-ante analysis) 형태의 연구가 아닌, 현재를 기준으로 과거에 실재했거나 발생했던 사건을 분석하는 사후분석(ex-post analysis) 형태로 분석하고자 한다.

본 연구의 사후분석 접근방법은, 과거의 농산물 가격과 수급상황이 과거 실제의 기상상황이 아닌 미래의 예상 기후로 변화하였을 때 어떻게 그리고 얼마나 변화하였을지 분석하는 것을 뜻한다. 이러한 접근방법은 기후변화가 농산물 시장에 미치는 영향분석을 장기 농산물 가격 전망을 통하지 않고도 가능하게 한다.

본 연구의 분석 대상은 기상변수에 큰 영향을 받고, 정부가 물가관리를 위해 특별히 수급 관리를 하는 5 대 노지채소(양파, 배추, 무, 마늘, 건고추) 중 하나인 양파이고, 사후분석 기간은 최근 5 년으로, 2014 년부터 2018 년까지이다.

양파의 생산액은 2017 년 기준 1 조 1,193 억 원으로 농업 총 생산액 46 조 780 억 원에서 차지하는 비중은 $2.5 \%$ 로 크진 않지만, 조미채소 생산액 3 조 6,729 억 원에서 차지하는 비율은 $30.5 \%$ 로 가장 큰 것으로 나타났다.

한편 양파는 2019 년 재배면적이 줄었음에도 불구하고 수확기의 온화한 기후로 인하여 단수가 증가하여 생산량이 크게 증가하였고, 그 결과로 2019 년 양파가격은 폭락하였다. 정부는 양파가격지지를 위하여 소비 진작과 수출증대 등 다양한 대응책을 제시하였지만 양파가격 안정화를 위해서는 보다 근본적인 수급대책이 필요하리라 생각된다.
양파수급의 주요한 결정요인으로 작용하는 기후환경 변화와 관련된 본 연구는 양파를 비롯한 노지채소 수급안정화에 관한 장기 정책수립에 중요한 기초자료로 이용될 수 있을 것으로 기대된다.

본 연구의 구성은 다음과 같다. 제 2 장은 기후변화와 관련된 선행연구를 정리하고, 제 3 장은 분석모형과 분석자료 그리고 분석방법인 사후분석 절차에 대하여 설명한다. 제 4 장은 분석 결과를 제시하고, 마지막 제 5 장은 결과를 요약하고 이에 대한 시사점들을 논한다.

\section{2. 선행연구 고찰}

기후변화가 농업에 미치는 영향과 관련된 연구는 기후변화로 인한 작물과 축산물의 생산성 변화와 같은 물리적 효과에 관한 연구, 그리고 생산성 변화로 인한 경제적 영향에 관한 분석으로 분류할 수 있다(Adams et al., 1998).

경제적 영향과 관련된 연구는 가상의 기후변화에 대한 객관적인 영향평가에서부터 기후변화에 대한 완화 및 적응 정책의 경제적 효과 분석(Pizer, 2002; Williges et al, 2017) 등으로 구분 할 수 있다.

경제적 영향 평가의 분석 방법은 기후변화 대응수단에 대한 비용편익 분석(Watkiss et al, 2015), 기후변화에 대한 생산자들의 최적화 반응을 반영한 최적화 모형(Chang, 2002) 등 다양한 방법 등이 있지만 가장 많이 이용되는 접근 방법은 일반균형모형과 부분균형모형을 들 수 있다.

기후변화는 국지적이지 않고 전 세계적인 현상이라는 측면에서 경제 내의 다양한 시장을 동시에 다룰 수 있고, 농산물 시장과 다른 시장들 간의 상호연관관계를 분석할 수 있는 일반균형모형이 기후변화가 농업에 미치는 영향과 관련된 연구에 광범위하게 이용되었다(Darwin, 2004; Palatnik \& Roson, 2012; Bosello et al, 2012; Calzadilla et al, 2013; Sands et al, 2014; Mushtaq, 2018).

Dmin(2004)은 경제변수, 온실가스 배출, 기후 전망에 대한 불확실성 때문에 기후변화가 농업부분에 미치는 영향에 대한 분석결과의 신뢰도가 낮다고 주장했다. 연산가능일반균형(CGE: Computable General Equilibrium) 모형을 이용한 Drwin(2004)의 분석결과에 의하면 경제상황을 1990 년대로 가정하였을 때 기후변화는 유럽의 1 인당 복지를 감소시키지만 좀더 나은 경제상황 하에서는 유럽의 1 인당 복지가 증가하는 것으로 나타났다. 그러나 이러한 불확실성에도 불구하고, 다양한 경제상황을 가정한 Dmin(2004)의 시나리오 분석에서 지구의 평균온도가 10 에서 $18^{\circ} \mathrm{C}$ 증가 할 때, 세계 곡물 생산은 항상 감소하고 가격은 상승하는 것으로 분석되었다.

Bosello et al. (2012) 는 CGE 모형을 사용하여 기후변화가 전 세계 경제에 미치는 영향을 분석하였다. 분석결과에 의하면 2050 년, 산업화 이전 시대와 비교하여 기온이 $192^{\circ} \mathrm{C}$ 상승하는 시나리오의 경우, 전 세계 
$\mathrm{GDP}$ 는 기후변화가 없는 경우를 가정한 시나리오에 비교하여 $0.5 \%$ 하락하는 것으로 분석되었다. 분석결과를 지역별로 세분화하면, 기온 상승으로 가장 이익을 보는 지역은 북유럽이고, 가장 피해를 보는 지역은 아프리카나 동남아시아의 저개발 국가인 것으로 나타났다. 또한 저개발국가의 피해는 대부분이 농업부문에서의 작물 생산성 저하에서 기인하는 것으로 분석되었다.

Calzadilla et al. (2013) 는 빗물(rainfed) 농업과 관개(imigated) 농업을 구분하고, 관개 농업의 명시적 생산 요소로 수자원을 포함하는 CGE 모형인 GTAP-W 모델을 이용하여 기후변화가 국제농업에 미치는 영향을 분석하였다. 분석결과에 의하면, 분석된 모든 기후변화 시나리오 하에서 식량생산과 GDP 가 하락하고 농산물 가격이 상승하는 것으로 나타났다.

앞에서 살펴본 일반균형모형의 경우, 전체 시장의 토지이용과 수자원 이용 등을 모형 내에서 내생화한다는 점, 그리고 농업시장과 그 외 시장간의 상호연관 관계를 고려한 거시적인 분석결과를 제시할 수 있다는 점 등 많은 장점이 있지만 기후변화로 인한 농산물 시장 내에서의 시장참여자들의 세밀한 의사결정과정을 모형화하는 데는 한계가 있다.

이와 반대로 농업부문 외의 시장을 외생변수 취급하는 농업 부분균형모형의 경우, 농업 외 시장과의 상호작용을 분석하는 데는 제한적이지만 농업 부문 혹은 특정 농산물시장의 수급구조 및 가격결정 과정을 비교적 자세히 묘사할 수 있다. 이러한 장점으로 인하여, 부분균형모형을 이용하여 기후변화가 농산물 시장에 미치는 영향을 분석한 다수의 연구가 존재한다(Key \& Tallard, 2012; Frank et al, 2014; Baldos \& Hertel, 2014; Frank et al, 2016; Nahar et al, 2018).

Key and Tallard(2012)는 OECD 와 FAO 에 의하여 개발 유지되고 있는 대표적인 농업 부분균형모형인 AGLNK-COSIMO 모형을 이용하여 탄소세(carbon tax)와 배출량 거래제도(emissions trading scheme)가 가축생산, 소비, 무역 그리고 궁극적으로 메탄 배출량에 미치는 영향을 추정하였다. 분석결과에 의하면 탄소세와 배출량 거래제도가 기후변화에 관한 유엔기본협약(UNFCC) 부속서 I (Annex I) 국가에 한정될 경우, 부속서 I 이외 국가들에서 증가된 메탄 방출량이 부속서 $\mathrm{I}$ 국가에서 감축한 메탄 방출량의 $2 / 3$ 를 상쇄하는 것으로 나타났다.

Baldos and Hertel (2014)는 식량안보 모듈을 포함한 부분균형모형을 이용하여 농업생산성과 기후변화가 미래 식량안보에 미치는 영향을 분석하였다. 분석결과에 의하면 기후변화의 불확실성, 인구와 바이오연료 수요의 증가에도 불구하고 소득과 농업생산성 증가로 2050 년까지 식량안보 상황이 개선 되는 것으로 전망되었다. 구체적으로는 에너지 섭취량이 $24 \%$ 증가하고, 영향실조 발생률이 $84 \%$ 감소 하는 것으로 전망되었다.

Nahar et al. (2018)는 기후변화가 방글라데시 쌀 농가와 쌀 시장에 미칠 잠재적 영향을 다지역 농가 부분균형모형(partial equilibrium multi-regional farm household model)을 이용하여 분석하였다. 분석결과에 따르면, 기후변화로 인한 재배면적과 생산성 감소로 쌀 생산량이 $2 \%$ 감소하고 이는 다시 쌀 소비 감소와 수입 증가과정을 거처서 최종적으로 쌀 가격을 $5.71 \%$ 상승시켰다. 또한 기후변화에 부정적인 영향을 받는 지역의 많은 농가들은 궁극적으로 농업을 포기하고 다른 직종으로 이직할 것으로 전망되었다.

한편 기후변화가 국내농업에 미치는 영향과 관련된 연구들은 기후에 가장 큰 영향을 받고, 중요 농산물로 인식되는 쌀과 노지채소 등을 대상으로 부분균형 모형을 이용한 연구가 중심을 이루고 있다. 이들 연구들은 많은 경우 균형대체모형(Davis and Espinoza, 1998)을 이용하여 기후변화가 대상 농산물 시장에 미치는 영향을 분석하였다. 그러나 균형대체모형은 여러 가지 장점에도 불구하고 비교정태 부분균형모형이라는 점에서, 기후변화에 대한 시장의 동태적 적응과정을 적절히 반영하는 데 한계가 있다.

본 연구는 비교정태분석에 기초한 기후변화와 관련된 기존 국내연구들의 한계점을 보완하기 위하여 동태 부분균형모형을 개발 이용하여 가상의 기후변화가 양파시장에 미치는 영향을 분석하였다. 기존 연구와 본 연구의 또 다른 중요한 차이점은 가상의 기후변화의 영향을 미래시점을 대상으로 한 사전분석(ex-ante analysis)이 아닌 과거시점을 기준으로 한 사후분석(ex-post analysis)을 적용 하였다는 데서 찾을 수 있다.

\section{3. 연구방법론}

\section{1. 분석모형}

본 연구는 기후변화와 같은 외부충격이 시간의 흐름에 따라 양파시장 전체에 미치는 영향을 분석하기 위하여 양파농가의 재배면적 결정부터 도매단계 소비자의 양파구입 결정까지 전 의사결정 과정을 모형화한 양파 연간 동태부분균형모형(dynamic partial equilibrium model)을 개발 이용하였다.

모형의 구조와 모형을 이용한 시뮬레이션 과정은 대표적인 농업정책전망 기관인 미국 FAPRI(Food and Agricultural and Research Institute) 방식에 기초한다(Meyers et al., 2010).

모형의 전체적인 구성은 <Figure 1>에서 보는 바와 같이, 재배면적, 단수, 생산량, 수입수요, 기말재고, 도매단계 소비자 수요 방정식 등으로 구성되어 있다.

기후변수와 추세변수로 설정된 단수함수를 제외한 모든 행태방정식들(behavioral equations)에 직간접적으로 영향을 미치는 시장청산가격(market deaning price)인 양파도매가격은 모형 내에서 
총공급과 총수요가 일치하는 균형조건 하에서 연립방정식(simultaneous equation system) 형태로 구하였다.

이러한 접근 방법은 기존의 국내 노지채소 부분균형 모형들에서 많이 이용되는 축차 모형(recursive model) 하에서 역수요 함수의 직접 추정을 통한 가격 도출방법과 차별되는 방식이다. 축차 모형은 수요와 공급이 가격과 동시에 결정되는 연립방정식 모형과 달리, 공급이 먼저 결정되면 이를 수요로 전환하고, 최종적으로 가격을 수요량의 함수로 설정 하여 추정한다.

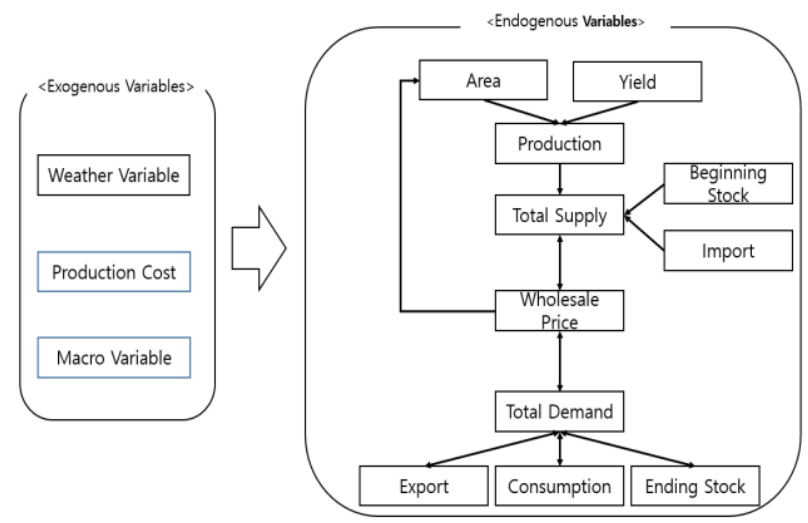

Figure 1: Flow Chart of Korean Onion Model

연립방정식 형식의 가격 도출방법은 역수요 함수 추정치에서 편의(bias)가 발생하는 축차 모형보다 통계적으로 일관적 일뿐만 아니라, 양파와 같이 저장수요가 존재하는 노지채소 시장을 좀 더 현실적으로 묘사한 방법이다.

역수요 함수를 통한 가격추정은 양파시장에서 가격이 양파수요를 결정 하는 것이 아닌 양파 수급량에 가격이 조정되는 것을 의미한다. 이러한 설정은 단기에 있어서 농산물의 비탄력적인 성격을 반영한 것이라고 할 수 있으나, 가격 변화에 저장을 통하여 일정부분 탄력적으로 반응 할 수 있는 양파 시장을 감안 할 때, 재고량, 소비량, 수입량 등을 가격의 함수로 1 차적으로 설정하고 총수요(소비, 기말재고, 수출)와 총공급(생산, 기초재고, 수입) 의 항등식을 통해 동시에 균형가격을 도출하는 것이 좀 더 현실 시장에 부합한 모형이라 할 수 있다(Park \& Kim, 2018).

분석모형의 중요한 차별점은 동태모형(dynamic model)이라는 점이다. 기후 변화가 농산물 시장에 미치는 영향에 관한 많은 선행연구들은 미래 $(t+1)$ 라는 특정 시점에서 평균적인 기후하의 시장과 가상의 기후하의 시장 상황을 비교하는 비교정태모형(comparative static model) 접근 방법을 이용하고 있다. 그러나 (t+1) 시점의 기후 변화의 효과는 변화 시점인 $(\mathrm{t}+1)$ 에만 한정되는 것이 아니라 $(\mathrm{t}+\mathrm{i}+1),(\mathrm{t}+\mathrm{i}+2),--(\mathrm{t}+\mathrm{i}+\mathrm{n})$ 시점까지 시장에서 그 영향의 정도가 변화하면서 누적되어 나타날 가능성이 크다.
이러한 기후변화의 동태적 영향을 사전분석이 아닌 사후분석 측면에서 설명하면, 과거 ( $(\mathrm{t}-1)$ 시점의 가상의 기후변화 효과는 (t-1) 시점에 제한되는 것이 아니라 (t-(-1-1)), (t-(i-2)), --, t 시점까지 그 영향이 변화하면서 누적되어 나타나는 것이다.

비교정태분석과 동태분석의 중요한 차이점은 외부환경 변화에 대한 시장의 적응과정이 누적되어 나타나느냐의 여부에 있다. 모형 내의 도매시장가격을 예를 들어 설명하면 과거 (t-1) 시점에 가상의 기후변화가 있을 경우 비교정태모형의 경우 (t-1) 시점에서 기후변화 효과만큼 가격이 변할 것이고, (t-(i-1)) 시점에서는 그 시점에서의 기후변화만큼 독립적으로 가격이 변할 것이다.

그러나 동태모형의 경우, (t-1) 시점에서 일어난 가상의 기후변화로 인한 가격변동에 양파 농가가 재배면적 변경으로 반응할 것이고, 이렇게 변경된 양파 재배면적은 (t-1) 시점의 시장뿐만 아니라 (t-(-1-1)) 시점의 시장에 반영되어서, (t-(i-1)) 시점의 가상의 기후변화 효과와 함께 누적되어 나타난다. 그 결과 동일한 기후변화가 양파가격에 미치는 영향이 비교정태분석보다 시장의 조정과정을 반영하여 가격변동 폭을 상쇄한 동태분석에서 작게 나타날 가능성이 크다 (Figure 2).

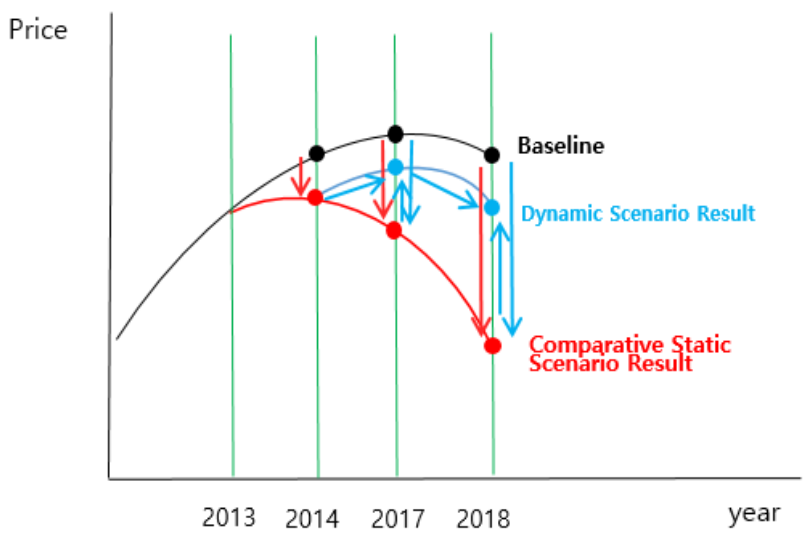

Figure 2: Comparison between Comparative Static and Dynamic Model Analysis

모형 내 내생변수들을 보다 구체적으로 살펴보면 아래와 같다.

\subsection{1. 재배면적 함수}

양파 재배배면적(ACR)은 Nerlove 의 부분조정모형에 기반하여 전년도 재배면적(ACR(-1)), 기대순수익(NETR)의 함수로 설정하였다.

$$
A C R=f(A C R(-1), N E T R)
$$

위 식에서 기대순수익은 Cagon 의 적응적 기대가설에 기초하여 단순히 전년도 가격과 비용의 함수가 아닌 가격과 생산비용 비율의 
과거 2 년 가중평균에 과거 2 년 가중평균 단수의 곱을 통하여 도출하였다. 가중치는 전년에 $70 \%, 2$ 년 전에 $30 \%$ 를 적용하였다.

\subsection{2 단수 함수}

양파의 단수(YD)는 수확기인 3 월의 평균기온(AVTEMP), 정식기인 전년도 11 월의 강수량(RAIN)과 기술발전을 반영하는 추세변수(TREND)로 설정하였다.

$Y D=f(A V T E M P, R A I N, T R E N D)$

\subsection{3. 생산량}

양파 생산량(Q)은 재배면적과 단수의 곱을 통하여 도출하였다.

$\mathrm{Q}=\mathrm{ACR} * \mathrm{YD}$

\subsection{4. 기말재고수요 함수}

양파의 기말재고수요(EST)는 거래적 수요를 나타내는 생산량(Q), 투기적 수요를 나타내는 실질도매시장가격( $\frac{N W P}{C P I}$ ) 그리고 기말재고수요의 동태성을 반영하는 전년도 기말재고인 기초재고(BST)의 함수로 설정하였다.

$$
E S T=f\left(Q, \frac{N W P}{C P I}, B S T\right)
$$

\subsection{5. 수입 함수}

양파의 수입수요(M)는 실질도매시장가격 $\left(\frac{N W P}{C P I}\right)$ 과 실질수입가격 $\left(\frac{I M P}{C P I}\right)$ 의 함수로 구성하였다.

$$
M=f\left(\frac{N W P}{C P I}, \frac{I M P}{C P I}\right)
$$

\subsection{6. 도매단계 1 인당 양파소비 함수}

도매단계 1 인당 양파소비(PERD)는 양파 실질도매가격( $\left.\frac{N W P}{C P I}\right)$ 과 실질가처분소득 $\left(\frac{D I N C}{C P I}\right)$ 의 함수로 설정하였다. 이렇게 설정된 1 인당 양파소비량은 추정 후 인구와의 곱을 통하여 모형 내에서 도매단계 소비량으로 도출된다.

$$
P E R D=f\left(\frac{N W P}{C P I}, \frac{D I N C}{C P I}\right)
$$

\subsection{7. 기초재고량과 수출량}

기초재고량(BST)은 전년도기말재고량(EST(-1))의 이월 량으로서 항등식 관계에 있다. 한편 수출량(X)은 전체 양파시장에서 차지하는 비중이
적은 관계로 모형 내에서 외부환경변화와 관계 없이 일정하다고 가정하였다.

\subsection{8. 도매시장가격}

도매시장 가격은 앞에서 언급한 바와 같이, 총수요(TD)와 총공급(TS)이 일치하는 균형 조건하의 연립방정식형태에서 반복계산(teration)을 통하여 구하였다.

자세한 도출과정은 식 (7)과 같다. 먼저 임의로 선택된 초기가격 $\left(N W P_{t, k-1}\right)$ 하에서 소비량(D), 수출량(X), 기말재고(EST)의 합인 총수요(TD)와 생산량(Q), 수입량(M), 기초재고량(BST)의 합인 총공급(TS)이 결정된다. 만약 초기가격하에서 초과수요가 존재할 때, 초기가격은 균형조정계수 $(\delta)$ 를 통해 상승하고, 초과공급이 존재할 때는 하락하는 과정을 총수요와 총공급이 일치하는 균형가격 $\left(N W P_{t, k}\right)$ 에 도달할 때까지 반복한다. 여기에서 (k)는 모형이 균형가격까지 도달하는 반복횟수이다.

$$
\begin{aligned}
& N W P_{t, k}=N W P_{t, k-1}-\delta(\mathrm{TS}-\mathrm{TD}), \\
& , \mathrm{k}=1 \sim \infty, 0<\delta<1 .
\end{aligned}
$$

\section{2. 분석 자료}

본 연구는 양파 연간동태부분균형모형 추정을 위하여 1988 년부터 2018 년까지의 연간 시계열 자료를 이용하였다. 재배면적, 단수, 생산량, 생산비 자료는 통계청 자료를 이용하였다. 수출입량과 수입단가는 관세청 자료, 재고량의 경우는 한국농촌경제연구원 자료를 사용하였다. 소비량 자료는 생산량, 기초재고량, 수입량의 합에서 기말재고량과 수출량을 뺀 잔차로 도출하였다. 도매가격은 한국농수산식품유통공사 자료를 이용하고, 단수추정에 사용된 기상자료는 기상청 국가기상데이터센터 자료를 이용하였다.

한편 재고량, 수출입량, 가격 자료는 회계연도 자료가 아닌 양파가 수확되어서 시장에 유통되는 연산연도(crop year or marketing year)를 기준으로 월간자료를 합산하여 이용하였다. 양파의 연산연도는 4 월부터 익년 3 월까지이다.

\section{3. 분석 방법}

기후변화가 농산물시장에 미치는 영향에 대한 일반적인 접근방법은 사전분석(ex-ante analysis)의 형태로 과거의 평균적인 날씨가 미래에도 계속된다는 가정하에 예측된 미래시장 상황을 비교의 기준이 되는 기준전망치(baseline)로 도출하고, 미래시점에서 평균적인 날씨가 아닌 변화된 기후 시나리오 하에서 도출된 미래시장 상황과 비교를 통하여 이루어진다. 
이와 달리 사후분석(ex-post analysis) 접근방법은 과거의 실제 기후 하에서 얻어진 실제 시장상황을 기준전망치(baseline)로 도출하고, 과거의 실제 기상상황이 아닌 미래의 예상 기후 시나리오 하에서 도출된 가상의 과거시장과 비교를 통하여 진행된다.

기후변화가 양파시장에 미칠 영향과 관련된 사후분석 절차를 양파 동태부분균형모형의 개별 행태방정식의 추정결과를 나타내는 식을 통하여 좀더 자세히 설명하면 다음과 같다.

첫째, 과거 실제 기후조건하에서의 양파시장 실제 수급현황과 가격을 추정된 모형의 시뮬레이션을 통해 기준전망치 추정값 ( $\widehat{Y_{B}}$ )과 기준전망치 추정 잔차항 $\left(\widehat{U_{B}}\right)$ 의 합인 기준전망치 실제값 $\left(Y_{B}\right)$ 로 나타낸다.

$$
\begin{aligned}
& Y_{B}=\widehat{Y_{B}}+\widehat{U_{B}} \\
& Y_{B}: \text { 기준전망치 실제값 } \widehat{Y_{B}}: \text { 기준전망치 추정값 } \\
& \widehat{U_{B}}: \text { 기준전망치 추정 잔차항 }
\end{aligned}
$$

둘째, 과거 가상의 기후변화를 적용한 시나리오 추정 결과를 모형 내 시뮬레이션을 통해 시나리오 추정 값 $\left(\widehat{Y}_{S}\right)$ 과 시나리오 추정 잔차항 $\left(\widehat{U_{S}}\right)$ 의 합인 시나리오 결과값 $\left(Y_{S}\right)$ 로 나타낸다.

$$
Y_{S}=\widehat{Y_{S}}+\widehat{U_{S}}
$$

$Y_{S}:$ 시나리오 결과값 $\widehat{Y}_{S}:$ 시나리오 추정값

$\widehat{U}_{S}:$ 시나리오 추정 잔차항

마지막으로, 사후분석을 통한 기후변화의 영향은 시나리오와 기준전망치의 차이로 구해진다.

$$
Y_{S}-Y_{B}=\widehat{Y_{S}}+\widehat{U_{S}}-\widehat{Y_{B}}-\widehat{U_{B}}
$$

사후분석 절차의 핵심적인 사항은 위 식에서 시나리오 추정 잔차항 $\left(\widehat{U_{S}}\right)$ 의 값이 기준전망치 추정 잔차항 $\left(\widehat{U_{B}}\right)$ 의 값과 같고, 시나리오 추정값 $\left(\widehat{Y_{S}}\right)$ 와 베이스라인 추정값 $\left(\widehat{Y_{B}}\right)$ 차이는 오직 기후변수 값의 차이일 뿐이라는 것이다.

$$
\begin{aligned}
& \widehat{U_{S}}=\widehat{U_{B}} \\
& Y_{S}-Y_{B}=\widehat{Y_{S}}+\widehat{U_{S}}-\widehat{Y_{B}}-\widehat{U_{B}}=\widehat{Y_{S}}-\widehat{Y_{B}}
\end{aligned}
$$

식 (11)의 가정이 의미하는 바는 기후변화의 영향은 오직 모형에서 명시적으로 설정된 변수들의 변화를 통해서만 투영되고, 잔차항으로 표현되는 기타 요인들은 기후변화에 반응하지 않는다는 것을 의미한다. 이러한 가정은 기후변화 시나리오 분석 시 모형 내 포함되지 않은 다른
기타 변수들의 영향을 억제함으로써 기후변화가 농산물 시장에 미치는 순효과(net effect)를 측정 가능하게 한다

\section{4. 연구결과}

\section{1. 추정결과}

모형 내의 개별 행태방정식들은 OLS 를 이용하여 추정하였다. 추정 결과 모든 추정치가 경제학 이론과 양파 시장의 현실에 부합한 것으로 나타났다. 또한 모든 변수들의 추정치가 $90 \%$ 이상의 유의계수 안에서 통계적으로 유의하였고 모든 방정식들이 자기상관이 없는 것으로 판명되었다.

추정결과를 정리한 표는 독립변수의 추정치, 유의성을 검정하기 위한 추정치의 P-value 값 모형 적합 정도를 표시하는 $R^{2}$ 값과 자기상관을 검정하는 BG-LM P-value 값으로 구성 하였다. 모든 함수식은 log-log 형태로 설정하여 추정하였기 때문에 추정된 계수 값들은 종속변수에 대한 독립변수의 탄력성을 의미한다. 모형의 유의성을 위해 추정과정에 더미변수를 내포하였지만 더미변수의 추정결과는 지면 제약 상 표에 포함하지 않았다.

\subsection{1 재배면적 추정결과}

재배면적은 예상한 바와 같이 전기 재배면적과 양파 기대 순수익에 양(+)의 반응을 보였다 기대순수익의 재배면적에 대한 탄력성은 0.34 로 선행연구들의 탄력성과 유사하게 추정되었다.

Table 1: Area Estimation Result

\begin{tabular}{|c|c|c|}
\hline Variable & Estimate & P-Value \\
\hline Constant & -0.141669 & 0.91 \\
\hline ACR(-1) & 0.743395 & $0.0000^{* * *}$ \\
\hline NETR & 0.347856 & $0.0005^{* * *}$ \\
\hline \multicolumn{2}{|c|}{$\mathrm{R}^{2}=0.88$, BG-LM P-Value $=0.70$} \\
\hline
\end{tabular}

$* * *, * *$, and * indicate significant level of $1 \%, 5 \%$, and $10 \%$ respe ctively.

\subsection{2 단수 추정결과}

양파단수는, 수확기인 3 월의 평균기온이 올라가면 증가하고, 정식기인 전년도 11 월의 강수량이 증가하면 하락 하는 것으로 나타났다. 한편 양파단수는 정식기 누적 강수량보다 수확기 평균기온에 상대적으로 더 큰 영향을 받는 것으로 추정되었다. 
Table 2: Yield Estimation Result

\begin{tabular}{|c|c|c|}
\hline Variable & Estimate & P-Value \\
\hline Constant & 8.50338 & $0.0000^{* * *}$ \\
\hline AVTEMP & 0.089036 & $0.0627^{*}$ \\
\hline RAIN & -0.03619 & $0.0074^{* * *}$ \\
\hline TREND & 0.081717 & $0.0000^{* * *}$ \\
\hline \multicolumn{2}{|c|}{$\mathrm{R}^{2}=0.87$, BG-LM P-Value $=0.58$} \\
\hline
\end{tabular}

$* * *, * *$, and * indicate significant level of $1 \%, 5 \%$, and $10 \%$ respe ctively.

\subsection{3. 기말재고 추정결과}

양파 기말재고는 기초재고와 생산량에 대해서는 양(+)의 반응을 나타내고, 투기적 수요를 반영한 실질가격에는 음(-)의 반응을 보였다.

Table 3: Ending Stock Estimation Result

\begin{tabular}{|c|c|c|}
\hline Variable & Estimate & P-Value \\
\hline Constant & -0.2399928 & 0.9318 \\
\hline $\mathrm{Q}$ & 0.4987 & $0.0236^{* *}$ \\
\hline$\frac{N W P}{C P I}$ & -0.62518 & $0.001^{* * *}$ \\
\hline $\mathrm{BST}$ & 0.484721 & $0.0001^{* * *}$ \\
\hline \multicolumn{2}{|c|}{$\mathrm{R}^{2}=0.88$, BG-LM P-Value $=0.32$} \\
\hline
\end{tabular}

$* * *, * *$, and $*$ indicate significant level of $1 \%, 5 \%$, and $10 \%$ respe ctively.

\subsection{4. 수입 추정결과}

양파 수입수요는 실질도매가격에는 정(+), 실질수입단가에는 부(-)의 반응을 하는 것으로 나타났다. 탄력성의 경우 실질국내가격에는 탄력적으로 반응한 반면, 실질수입단가에는 비탄력적으로 반응하는 것으로 추정되었다.

Table 4: Import Estimation Result

\begin{tabular}{|c|c|c|}
\hline Variable & Estimate & P-Value \\
\hline Constant & 2.740739 & 0.19 \\
\hline$\frac{N W P}{C P I}$ & 2.397016 & $0.0000^{* * *}$ \\
\hline$\frac{I M P}{C P I}$ & -0.467606 & $0.09^{*}$ \\
\hline \multicolumn{2}{|c|}{$\mathrm{R} 2=0.93$, BG-LM P-Value $=0.24$} \\
\hline
\end{tabular}

$* * *, * *$, and $*$ indicate significant level of $1 \%, 5 \%$, and $10 \%$ respe ctively.

\subsection{1 인당소비 추정결과}

추정결과에 의하면 실질 양파가격이 증가하면 양파소비량이 감소하지만 가격변화에 비탄력적으로 반응하는 것으로 나타났다. 한편 실질 가처분 소득에 양(+)의 반응을 하는 정상재로 추정되었다.
Table 5: PRED Estimation Result

\begin{tabular}{|c|c|c|}
\hline Variable & Estimate & P-Value \\
\hline Constant & -3.872271 & $0.0000^{* * *}$ \\
\hline$\frac{N W P}{C P I}$ & -0.168831 & $0.0005^{* * *}$ \\
\hline$\frac{D I N C}{C P I}$ & 0.796407 & $0.0000^{* * *}$ \\
\hline \multicolumn{2}{|c|}{$\mathrm{R} 2=0.95$, BG-LM P-Value $=0.97$} \\
\hline
\end{tabular}

$* * *, * *$, and $*$ indicate significant level of $1 \%, 5 \%$, and $10 \%$ respe ctively.

\section{2. 기준전망치(Baseline) 시뮬레이션 결과}

본 연구에서는 가상의 기후변화가 양파시장에 미치는 영향을 과거 양파수급상황을 통하여 유추하고자 양파 동태부분균형모형의 추정치에 기초한 시뮬레이션을 통하여 최근 5 년간 (2014 2018)의 실제 양파시장 수급상황을 도출하였다.

이는 기후변화를 나타내는 시나리오 분석의 비교의 대상이 되는 벤치마크 역할을 한다. 2014 년부터 2018 년까지의 실제 양파 재배면적, 단수, 생산량, 수입량, 기말재고량, 소비량, 도매가격은 <Table 6>과 같다. 지면의 제약으로 2016, 2017 년의 시뮬레이션 결과는 생략하였다.

Table 6: Baseline Simulation Results

\begin{tabular}{|c|c|c|c|}
\hline & $\mathbf{2 0 1 4}$ & $\mathbf{2 0 1 5}$ & $\mathbf{2 0 1 8}$ \\
\hline Area(ha) & 23,911 & 18,015 & 26,425 \\
\hline Yield(kg/10a) & 6,649 & 6,072 & 5,756 \\
\hline $\begin{array}{c}\text { Production } \\
\text { (ton) }\end{array}$ & $1,589,957$ & $1,093,932$ & $1,520,969$ \\
\hline Import(ton) & 24,033 & 214,878 & 73,965 \\
\hline Ending Stock(ton) & 58,694 & 14,463 & 30,497 \\
\hline $\begin{array}{c}\text { Consumption } \\
\text { (ton) }\end{array}$ & $1,587,117$ & $1,352,817$ & $1,578,297$ \\
\hline Price(won/kg) & 560 & 1,313 & 711 \\
\hline
\end{tabular}

\section{3. 시나리오 시뮬레이션 결과}

PCC 5 차 평가보고서에서는 대표농도 경로(RCP. Representative Concentration Pathways)를 새로운 기후변화 시나리오로 사용하고 있다. $\mathrm{RCP}$ 시나리오는 온실가스 감축노력 정도에 따라 RCP26, RCP4.5, RCP6.0, $\mathrm{RCP} 8.5$ 네 가지로 구성되어 있다.

본 연구는 4 종의 시나리오 중 현재 추세로 저감 없이 온실가스가 배출되는 경우를 가정한 RCP8.5 하의 기후조건이 양파시장에 미치는 
영향을 분석하였다. 가장 극단적인 상황을 가정한 RCP8.5 시나리오를 선택한 이유는 우리나라의 소극적인 기후변화 대응상황을 반영한 것이다. 2019 년 12 월에 발표된 '기후변화대응지수 (CCPI Climate Change Performance Index) 2020'(Burck et al, 2019)에 의하면 우리나라의 기후변화에 대한 대응은 평가대상 61 개국 중 58 위로 최하위급으로 평가 받았다.

$\mathrm{RCP}$ 온실가스전망에 따른 기상청의 우리나라 기후변화 전망에 의하면, RCP8.5 시나리오의 경우 21 세기 후반에 우리나라 기온은 현재대비 $4.7^{\circ} \mathrm{C}$ 상승하고, 강수량은 $13.1 \%$ 증가하는 것으로 전망되었다. 이러한 RCP8.5 하의 기후가 양파시장에 미치는 영향을 앞에서 언급한 사후분석을 통하여 분석하기 위해 본 연구는 다음과 같은 가상의 시나리오를 설정하였다.

시나리오: 2014 년부터 2018 년까지 기온과 강수량이 실제 관측된 기온과 강수량보다 각각 $4.7 C^{\circ}, 13.1 \%$ 증가함.

\subsection{1 비교정태 시뮬레이션 결과}

본 연구는 분석모형의 동태적 특징을 비교정태 분석 결과와 비교를 통하여 제시하기 위하여 동태 시뮬레이션 결과에 앞서 비교정태분석에 기초한 시나리오 시뮬레이션 결과를 논하고자 한다.

앞에서 설명한 바와 같이 비교정태모형에 입각한 분석은 기후변화와 같은 외부충격에 시장의 반응이 충격이 일어난 시점에 한정되고, 차기에 일어난 또 다른 충격에 대한 영향은 그 전에 일어난 충격과 독립되어서 차기 시점에서만 한정되어 시장에 반영된다.

이러한 비교정태모형에 입각한 시나리오분석 결과를 재현하기 위하여 본 연구는 2014 년부터 2018 년까지 가상의 기후변화가 양파시장에 미치는 영향을 매해 독립적으로 다섯 번의 시뮬레이션을 통하여 시나리오 결과를 도출하였다(<Table 7>).

먼저 2014 년의 양파시장을 통하여 RCP8.5 시나리오의 영향을 살펴보면, 기온이 $4.7^{\circ} \mathrm{C}$, 강수량이 $13.1 \%$ 증가할 때 양파의 단수는 2014 년 실제 기후 하의 단수를 나타내는 기준전망치보다 $4.38 \%$ 증가하는 것으로 분석되었다. 이는 수확기의 기온상승으로 인한 단수 증가요인이 정식기의 강수량 증가로 인한 단수 감소요인보다 크기 때문이다.

한편 재배면적의 경우 기후변화로 인한 단수증가에 영향을 받지 않는 것으로 나타났다. 이는 양파재배농가의 재배면적결정은 수확 이후에 나타나는 당해 년도의 가격이 아닌 전년과 2 년 전의 가격에 의해서 결정되도록 모형이 설정되어있기 때문이다. 생산량은 단수증가가 반영되어서 기준전망치 대비 $4.38 \%$ 증가하였다.

생산량 증가는 도매가격을 하락시켰고, 이는 다시 수입량의 $36.7 \%$ 하락, 소비량의 $3.27 \%$ 증가를 가져왔다. 한편 생산량에는 양 $(+)$, 가격에는 음(-)의 반응을 하는 기말재고량의 경우 생산량 증가와 가격하락으로 인하여 $15.1 \%$ 증가하였다. 한편 모형 내에서 총수요, 총공급과 동시에
결정되는 가격의 경우 최종적으로 기준전망치 대비 $17.37 \%$ 하락하는 것으로 분석되었다.

2014 년 이후의 2015 년부터 2018 년까지의 기후변화에 대한 양파시장의 반응은 정도의 차이는 있지만 2014 년과 같은 방향으로 움직이는 것으로 분석되었다.

Table 7: Impacts of RCP8.5 Scenario on Onion Market by C omparative Static Model

\begin{tabular}{|c|c|c|c|}
\hline & $\mathbf{2 0 1 4}$ & $\mathbf{2 0 1 5}$ & $\mathbf{2 0 1 8}$ \\
\hline Area(ha) & $\begin{array}{c}23,911 \\
(0 \%)\end{array}$ & $\begin{array}{c}18,015 \\
(0 \%)\end{array}$ & $\begin{array}{c}26,425 \\
(0 \%)\end{array}$ \\
\hline Yield & 6,941 & 6,339 & 5,971 \\
(kg/10a) & $(4.38 \%)$ & $(4.38 \%)$ & $(3.74 \%)$ \\
\hline Production & $1,659,595$ & $1,141,883$ & $1,577,866$ \\
(ton) & $(4.38 \%)$ & $(4.38 \%)$ & $(3.74 \%)$ \\
\hline Import(ton) & 15,213 & 183,168 & 54,508 \\
& $(-36.7 \%)$ & $(-14.76 \%)$ & $(-26.31 \%)$ \\
\hline Ending Stock(ton) & 67,558 & 15,404 & 33,634 \\
& $(15.10 \%)$ & $(6.51 \%)$ & $(10.29 \%)$ \\
\hline Consumption & $1,639,070$ & $1,368,116$ & $1,612,599$ \\
(ton) & $(3.27 \%)$ & $(1.13 \%)$ & $(2.17 \%)$ \\
\hline Price & 462 & 1,229 & 626 \\
(won/kg) & $(-17.37 \%)$ & $(-6.44 \%)$ & $(-11.96 \%)$ \\
\hline
\end{tabular}

Note: Figures in parentheses indicate percentage differences between sc enario and baseline.

특히 재배면적의 경우 2014 년과 마찬가지로 기후변화에 반응하지 않았다. 이러한 이유는 비교정태모형의 경우 외부환경변화에 대한 시장의 반응이 시간의 흐름에 따라 누적되어서 조정되는 것이 아니라 매 시기에 일어나는 외부환경 변화에 독립적으로 반응하기 때문이다. 즉 시간의 흐름에 따른 시장의 조정과정을 반영하지 못하는 비교정태분석의 한계점을 나타내는 결과라 고 해석할 수 있다.

\subsection{2. 동태 시뮬레이션 결과}

RCP8.5 시나리오 하의 기후변화가 양파시장에 미치는 영향을 동태모형을 통하여 분석한 결과는 <표 8>과 같다. 비교정태분석과 달리 동태분석의 시뮬레이션은 2014 년부터 2018 년까지 가상의 기후변화에 대한 시장의 반응이 과거의 영향이 누적되면서 한 번의 시뮬레이션을 통해 동시적으로 분석되었다.

먼저 2014 년의 영향을 살펴 보면 비교정태분석과 동일하다는 것을 알 수 있다. 이는 모형 내에서 기후변화의 충격이 2014 년부터 시작되는 것으로 시뮬레이션을 하였기 때문에 2014 년 이전의 기후변화와 관련된 영향이 비교정태와 동태분석 모두 없기 때문이다. 
그러나 2014 년 이후의 시장에서는 과거 시장에서의 시장참여자들의 기후변화에 대한 대응반응이 차기 년도의 시장에 누적되어 반영되면서 단수를 제외한 모든 변수들이 비교정태분석과 유의미하게 차별화된 시장의 조정결과를 보이는 것으로 나타났다.

한편 비교정태분석과 동태분석에서 단수의 변화가 동일하게 분석된 이유는 단수의 경우는 가격의 함수가 아닌 단순히 기후변수와 추세변수의 함수로 설정되어 있기 때문이다.

2015 년의 결과를 자세히 살펴보면 먼저 양파재배면적이 기준전망치 대비 $2.47 \%$ 하락한 것으로 분석되었다. 이러한 결과는 양파재배농가가 2014 년의 기후변화로 인한 가격하락에 2015 년 양파재배면적을 감축하는 것으로 반응하기 때문이다. 이러한 재배면적의 감소로 인하여, 단수의 증가가 그대로 생산량의 증가로 이어진 비교정태분석과 달리 생산량은 $18 \%$ 증가에 그치는 것으로 나타났다.

Table 8: Impacts of RCP8.5 Scenario on Onion Market by Dynamic Model

\begin{tabular}{|c|c|c|c|}
\hline & $\mathbf{2 0 1 4}$ & $\mathbf{2 0 1 5}$ & $\mathbf{2 0 1 8}$ \\
\hline Area(ha) & $\begin{array}{c}23,911 \\
(0 \%)\end{array}$ & $\begin{array}{c}17,569 \\
(-2.47 \%)\end{array}$ & $\begin{array}{c}25,994 \\
(-1.63 \%)\end{array}$ \\
\hline Yield & 6,941 & 6,339 & 5,971 \\
(kg/10a) & $(4.38 \%)$ & $(4.38 \%)$ & $(3.74 \%)$ \\
\hline Production & $1,659,595$ & $1,113,622$ & $1,552,149$ \\
(ton) & $(4.38 \%)$ & $(1.80 \%)$ & $(2.05 \%)$ \\
\hline Import & 15,213 & 196,432 & 62,686 \\
(ton) & $(-36.7 \%)$ & $(-8.58 \%)$ & $(-15.25 \%)$ \\
\hline Ending Stock & 67,558 & 15,992 & 33,521 \\
(ton) & $(15.10 \%)$ & $(10.57 \%)$ & $(9.92 \%)$ \\
\hline Consumption & $1,639,070$ & $1,361,396$ & $1,596,798$ \\
(ton) & $(3.27 \%)$ & $(0.63 \%)$ & $(1.17 \%)$ \\
\hline Price & 462 & 1,265 & 664 \\
(won/kg) & $(-17.37 \%)$ & $(-3.68 \%)$ & $(-6.67 \%)$ \\
\hline
\end{tabular}

Note: Figures in parentheses indicate percentage differences between sc enario and baseline.

생산량의 증가는 가격하락과 이로 인한 수입감소, 기말재고와 소비량 증가를 불러오는 것으로 분석되었다. 그러나 그 영향은 비교정태분석과 비교 시 상대적으로 작은 것으로 나타났다. 이러한 시장의 동태조정과정을 반영한 분석결과는 2016, 2017, 2018 년에도 유사하게 나타났다.

동태 시뮬레이션결과(<Table 8)를 비교정태 시뮬레이션 결과(<Table 7>)와 비교해 보면 동일한 기후변화에 따른 동일한 단수변화에도 불구하고 가상의 기후변화가 시작된 2014 년을 제외한 모든 해에서 동태분석의 결과가 비교정태분석보다 상대적으로 작게 나타났다. 이는 기상변화라는 외부충격에 시장참여자들이 적절하게 반응함으로써 그 충격의 정도를 상쇄시킨 결과로 해석할 수 있다.

본 연구는 RCP8.5 시나리오하의 기후변화가 2014 년부터 2018 년 양파시장에 일어났을 경우에 매해 양파시장의 수급과 가격에 미칠 영향(<Table 8>)에 더하여, 이러한 변화로 인한 5 년간의 전년대비 가격 변화율을 실제 전년대비 가격변화율과 비교하였다.

농가와 농업정책 당국자들의 단기에서의 주요 관심사는 기후변화와 같은 외부충격으로 인한 가격의 폭등과 폭락을 방지하거나 완화시켜서 농업소득 보장과 소비자 물가안정을 추구하는 것이다. 한편 중장기적인 목표는 가격변동률 완화를 통한 시장가격의 안정화로 시장의 예측가능성을 높여서 재배면적 결정 혹은 지원정책 결정과 같은 의사결정 과정의 불확실성을 완화하는 데 있다고 할 수 있다.

Table 9: Price Variation Rates

\begin{tabular}{|c|c|c|c|c|}
\hline \multirow{2}{*}{} & \multicolumn{2}{|c|}{$\begin{array}{c}\text { Actual Climate } \\
\text { Conditions }\end{array}$} & \multicolumn{2}{c|}{$\begin{array}{c}\text { Climate Conditions } \\
\text { under RCP8.5 } \\
\text { Scenario }\end{array}$} \\
\cline { 2 - 5 } & $\begin{array}{c}\text { Price } \\
(\text { Won/kg) }\end{array}$ & $\begin{array}{c}\text { Variation } \\
\text { Rate } \\
\text { (\%) }\end{array}$ & $\begin{array}{c}\text { Price } \\
(\text { Won/kg) }\end{array}$ & $\begin{array}{c}\text { Variation } \\
\text { Rate (\%) }\end{array}$ \\
\hline 2014 & 560 & 83 & 462 & 121 \\
\hline 2015 & 1313 & 57 & 1265 & 63 \\
\hline 2016 & 1001 & 31 & 950 & 33 \\
\hline 2017 & 1087 & 8 & 1038 & 8 \\
\hline 2018 & 711 & 53 & 664 & 56 \\
\hline Average & 934 & 46 & 876 & 56 \\
\hline $\begin{array}{c}\text { Coefficient of } \\
\text { variation }\end{array}$ & & & & 0.68 \\
\hline
\end{tabular}

이에 본 연구는 기후변화로 인한 양파 수급 및 가격의 변화가 궁극적으로 가격변동률에 미치는 영향을 살펴보았다. <Table 9>에 의하면 RCP8.5 하의 기후조건이 2014 년부터 2018 년 양파시장에 적용되었을 때의 5 년 평균 전년대비 양파가격 변동률은 $56 \%$ 로, 실제 기후조건하의 최근 5 년 평균 전년대비 양파가격 변동률 $46 \%$ 보다 변동성이 커지는 것으로 분석되었다. 또한 평균에서의 이탈 정도를 측정하는 변이계수도 RCP8.5 시나리오 하에서는 0.68 로 실제 기후조건하에서 도출된 값 0.58 에 비해 변동률이 큼을 알 수 있다.

<표 9>의 분석결과는, RCP8.5 의 기후변화가 단수증가로 단순히 양파가격을 하락시킬 뿐만 아니라 중장기적으로 가격변동률을 증가시켜서 시장의 안정성을 저해하는 요소로 작용할 수 있다는 점을 보여준다.

\section{5. 결론 및 시사점}




\section{1. 연구결과의 요약}

기후변화가 농산물시장에 미치는 영향과 관련된 사전분석(ex-ante analysis)들은 많은 경우 최소 10 년 이상에서 100 년에 가까운 장기 전망이라는 점에서 농산물 가격의 장기전망을 필요로 한다. 이러한 장기 가격전망은 기후변화와 관련된 농산물시장 연구의 주요한 제약요인으로 작용한다.

기후변화와 관련된 이러한 사전분석의 어려움을 완화하고자 본 연구는 최근(2019 년) 가격폭락을 겪었던 양파 시장을 대상으로 RCP8.5 시나리오, 즉 기온이 $4.7^{\circ} \mathrm{C}$ 상승하고 강수량이 $13.1 \%$ 증가하는 기후조건이 2014 년부터 2018 년의 실제 양파시장에 적용되었다면 미쳤을 가상의 영향을 동태부분균형모형을 이용하여 사후분석(ex-post analysis)하였다.

분석결과, RCP8.5 하의 기후조건이 2014 년부터 2018 년에 적용된다면, 양파의 단수는 최소 $3.74 \%$ 에서 최대 $4.69 \%$ 가량 증가하는 것으로 전망되었다. 이러한 단수증가에 비교정태분석의 경우 양파 도매가격은 최소 $6.44 \%$ 에서 최대 $17.37 \%, 5$ 년 평균가격이 $1128 \%$ 하락하는 것으로 나타나는데 비해 동태분석의 경우 양파도매가격은 최소 $3.68 \%$ 에서 최대 $17.37 \%, 5$ 년 평균가격이 $7.47 \%$ 하락하는 것으로 분석되었다. 이는 동태분석에서 시간의 흐름에 따라 시장참여자들이 변화에 적응한 결과로 해석할 수 있다.

또한 RCP8.5 기후조건하의 5 년간의 평균 전년대비 가격변동률은 $56 \%$ 로, 실제 기후하의 5 년간의 평균 전년대비 가격변동률 $46 \%$ 보다 변동성이 큰 것으로 나타났다. 이러한 분석결과는 기후변화로 인한 양파의 단수증가는, 양파시장에서 단기의 가격하락뿐만 아니라 중장기의 가격불안정성의 요인으로 작용할 가능성이 크다는 점을 나타낸다.

\section{2. 연구의 시사점}

기후변화에 대한 농업부문의 대응방안은 기술적인 면과 경제적인 면으로 분리 할 수 있다. 기술적인 측면은 기후변화로 인한 농업생산성 저하를 완화시키는 방법으로서 고온과 다우에 적합한 신품종 개발과 그에 맞는 새로운 농법 개발, 더 나아가서는 새로운 기후에 맞는 작목전환 등을 들 수 있을 것이다(Lybbert \& Sumner, 2012).

그러나 분석결과에 의하면 기온상승과 강수량 증가로 대표되는 기후변화에 연구 대상 품목인 양파 단위당 생산량은 하락하지 않고 증가하는 것으로 나타났다. 그리고 양파단수의 증가는 단기적으로는 가격하락, 중장기적으로는 가격변동률 증가로 인한 가격안정성 저해 요인으로 작용 하는 것으로 분석되었다.
분석결과가 시사하는 바는, 기후변화에 대한 양파농가와 양파시장 관련 정책당국자들의 적절한 대응방안은 단수증가를 위한 품종개발과 같은 기술적인 측면보다는, 가격안정화를 위한 경제적인 측면에서 찾아야 한다는 점이다.

기후변화와 관련된 양파 및 주요 노지채소의 가격안정화를 위한 대응방안을 살펴보면 아래와 같다. 첫째, 기후변화로 인한 농산물 생산량 변화와 이에 따른 가격변화 정보를 시장 출하 전 사전적으로 적시에 제공할 수 있도록 농업 관측 정보의 고도화가 필요하다. 이를 위해서는 예산 증가를 통해 농업 관측 관련 조사 인원을 늘리고, 여러 정부 부처에 나누어져 있는 농업 관측 업무를 집중화해서 효율적으로 다룰 수 있는 행정체계의 변화가 필요하리라 본다.

둘째, 농업 관측 고도화가 가격 안정화를 위한 사전적 대응방안이라면 단수 증가 혹은 하락에 따른 가격의 불안정성과 그로 인한 농업소득의 불안정성을 사후적으로 완화할 수 있는 대응방안은 계약재배 확대, 국산 노지채소 수매물량 확대 및 효율적인 재고관리, 효과적인 산지 폐기를 위한 유통명령제 강화 등을 들 수 있다.

마지막 대응방안은 보다 장기적인 것으로서 탄소세, 배출량 거래제도와 같이 온실가스 배출을 궁극적으로 줄일 수 있는 법적 제도들의 도입과 제도들의 효과적인 운영을 들 수 있다.

\section{3. 연구의 한계점 및 향후 연구방향}

본 연구는 기후변화가 농산물 시장에 미치는 영향을 사전분석이 아닌 사후분석으로 접근하였다는 점에서 선행연구들과 차별점이 있다. 또한 본 연구는 동태부분균형 모형의 시뮬레이션 과정의 변화를 통하여 기후변화가 농산물시장에 미치는 영향의 비교정태 분석결과와 동태 분석결과를 도출하였다. 이를 통한 분석 결과의 비교는 기후변화에 농산물 시장이 동태적으로 반응하는 과정을 좀더 명시적으로 설명 가능하게 하였다.

이러한 기여점들에도 불구하고 본 연구는 연구의 대상이 양파라는 단일 품목에 한정되어 있어 기후변화로 인한 양파와 다른 노지채소들과의 대체 과정을 적절히 모형에 반영하지 못한다는 한계점을 가지고 있다.

또한 본 연구는 양파시장을 지역별로 구분하지 않고 전국을 대상으로 하여 지역별 차이점을 반영하지 못한 한계가 존재한다. 이러한 한계점들은 향후 연구에서 연구 범위확대를 통하여 보완하고자 한다.

\section{References}

Abdul-Razak, M., \& Kruse, S. (2017). The adaptive capacity of smallholder farmers to climate change in the Northern Region of Ghana. Climate Risk Management, 17, 104-122. 
Adams, R. M., Hurd, B. H., Lenhart, S., \& Leary, N. (1998). Effects of global climate change on agriculture: an interpretative review. Climate Research, 11, 19-30.

Afroz, R., Muhibbullak, M., \& Morshed, M. N. (2019). Factors Affecting the Intention of the Rice Farmers to Adopt the Integrated Cash Waqf Environmental Protection Model: An Empirical Study in Kedah Malaysia. Journal of Asian Finance, Economics and Business, 6(4), 189-199.

Amamoua, H., Sassib, M.B., Aouadic, H., Khemirid, H., Mahouachie, M., Beckersa, Y., \& Hammamia, H. (2018). Climate change-related risks and adaptation strategies as perceived in dairy cattle farming systems in Tunisia. Climate Risk Management, 20, 38-49.

Baldos, U. L. C., \& Hertel, T. W. (2014) Global food security in 2050: the role of agricultural productivity and climate change. Australian Journal of Agricultural and Resource Economics, 58, 554-570.

Bosello, F., Eboli, F., \& Pierfederici, R. (2012). Assessing the Economic Impacts of Climate Change - An Updated CGE Point of View. FEEM Working Paper No. 2. 2012. Retrieved November 1, 2019, from https://www.feem.it/en/publications.

Burck, J., Hagen, U., Hohne, N., Nascimento, L., \& Bals, C. (2019). The Climate Change Performance Index 2020. Germanwatch, NewClimate Institute \& Climate Action Network. Retrieved December 15, 2019, from https://www.climate-change-performance-index.org/theclimate-change-performance-index-2020.

Calzadilla, A., Rehdanz, K., Betts, R., Falloon, P., Wiltshire, A., \& Tol, R. S. J. (2013) Climate change impacts on global agriculture. Climate Change, 120, 357-374.

Chang, C.-C. (2002). The Potential Impact of Climate Change on Taiwan's Agriculture. Agricultural Economics, 27, 51-64.

Darwin, R. (2004). Effects of greenhouse gas emissions on world agriculture, food consumption, and economic welfare. Climate Change, 66, 191-238.

Davis, G. C., \& Espinoza, M. C. (1998). A Unified Approach to Sensitivity Analysis in Equilibrium Displacement Models. American Journal of Agricultural Economics, 80, 868-879.

Frank, S., Witzke, H.-P., Zimmermann, A., Havlik, P., \& Ciaian, P. (2014). Climate change impacts on European agriculture: a multi model perspective. Paper prepared for presentation at the EAAE 2014 Congress 'Agri-Food and Rural Innovations for Healthier Societies'. Ljubljana, Slovenia.

Frank, S., Bottcher, H., Gusti, M., Havlik, P., Klaassen, G, Kindermann, G., \& Obersteiner, M. (2016). Dynamics of the land use, land use change, and forestry sink in the European Union: the impacts of energy and climate targets for 2030. Climate Change, 138, 253-266.

Georgopoulou, E., Mirasgedis, S., Sarafidis, Y., Vitaliotou, M., Lalas, D.P. Theloudis, I., Giannoulaki, K.-D., Dimopoulos, D., \& Zavras, V. (2017). Climate change impacts and adaptation options for the Greek agriculture in 2021-2050: A monetary assessment. Climate Risk Management, 16, 164-182.

IPCC. (2013). Climate Change 2013: The Physical Science Basis. Contribution of Working Group I to the Fifth Assessment Report of the Intergovernmental Panel on Climate Change [Stocker, T.F., D. Qin, G.-K. Plattner, M. Tignor, S.K. Allen, J. Boschung, A. Nauels, Y. Xia, V. Bex and P.M. Midgley (eds.)]. Cambridge University Press, Cambridge, United Kingdom and New York, NY, USA.

IPCC. (2014a). Climate Change 2014: Impacts, Adaptation, and Vulnerability. Part A: Global and Sectoral Aspects. Contribution of Working Group II to the Fifth Assessment Report of the Intergovernmental Panel on Climate Change [Field, C.B., V.R. Barros, D.J. Dokken, K.J. Mach, M.D. Mastrandrea, T.E. Bilir,M. Chatterjee, K.L. Ebi, Y.O. Estrada, R.C. Genova, B. Girma, E.S. Kissel, A.N. Levy, S. MacCracken, P.R. Mastrandrea, and L.L. White (eds.)]. Cambridge University Press, Cambridge, United Kingdom and New York, NY, USA.

IPCC. (2014b). Climate Change 2014: Mitigation of Climate Change. Contribution of Working Group III to the Fifth Assessment Report of the Intergovernmental Panel on Climate Change [Edenhofer, O., R. Pichs-Madruga, Y. Sokona, E. Farahani, S. Kadner, K. Seyboth, A. Adler, I. Baum, S. Brunner, P. Eickemeier, B. Kriemann, J. Savolainen, S. Schlomer, C. von Stechow, T. Zwickel and J.C. Minx (eds.)]. Cambridge University Press, Cambridge, United Kingdom and New York, NY, USA.

Katha, J., Mushtaqa, S., Henry, R., Adeyinkaa, A., Stone, R., Marcussena, T., Kouadioa, L. (2019). Spatial variability in regional scale drought index insurance viability across Australia's wheat growing regions. Climate Risk Management, 24, 13-29.

Key, N., \& Tallard, G. (2012). Mitigating methane emissions from livestock: a global analysis of sectoral policies. Climate Change, $112,387-414$.

Lybbert, T. J., \& Sumner, D. A. (2012). Agricultural technologies for climate change in developing countries: Policy options for innovation and technology diffusion. Food Policy, 37, 114123.

Mushtaq, S. (2018). Managing climate risks through transformational adaptation: Economic and policy implications for key production regions in Australia, Climate Risk Management, 19, 48-60.

Meyers, W. H., Westhoff, P., Fabiosa, J.F., \& Hayes, D. J. (2010) The FAPRI global modeling sysytem and outlook process. Journal of International Agricultural Trade and Development, 6(1), 1-19.

Nahar, A., Luckstead, J., Wailes, E. J., \& Alam, M. J. (2018). An assessment of the potential impact of climate change on rice farmers and markets in Bangladesh. Climate Change, 150, 289-304.

Palatnik, R. R., \& Roson, R. (2012). Climate change and agriculture in computable general equilibrium models: alternative modeling strategies and data needs. Climate Change, 112, 1085-1100.

Park, S. Y., \& Kim, I. S. (2018). The Economic Impact of Government Purchases on the Price Volatility of Korean Dried Red Pepper. International Journal of Industrial Distribution \& Business, 9(10), 73-82.

Pizer, W. A. (2002). Combining price and quality control to mitigate global climate change. Journal of Public Economics, 85, 409-434.

Porter, J.R., L. Xie, A.J. Challinor, K. Cochrane, S.M. Howden, M.M. Iqbal, D.B. Lobell, and M.I. Travasso (2014). Food security and food production systems. In: Climate Change 
2014: Impacts, Adaptation, and Vulnerability. Part A: Global and Sectoral Aspects. Contribution of Working Group II to the Fifth Assessment Report of the

Intergovernmental Panel on Climate Change [Field, C.B., V.R. Barros, D.J. Dokken, K.J. Mach, M.D. Mastrandrea,

T.E. Bilir, M. Chatterjee, K.L. Ebi, Y.O. Estrada, R.C. Genova, B. Girma, E.S. Kissel, A.N. Levy, S. MacCracken, P.R. Mastrandrea, and L.L. White (eds.)]. (pp. 485-533), Cambridge University Press, Cambridge, United Kingdom and New York, NY, USA.

Sands, R. D., Forster, H., Jones, C. A., \& Schumacher, K. (2014). Bio-electricity and land use in the Future Agricultural Resources Model (FARM). Climate Change, 123, 719-730.

Smith P., M. Bustamante, H. Ahammad, H. Clark, H. Dong, E. A. Elsiddig, H. Haberl, R. Harper, J. House, M. Jafari, O. Masera, C. Mbow, N. H. Ravindranath, C. W. Rice, C. Robledo Abad, A. Romanovskaya, F. Sperling, \& F. Tubiello (2014).
Agriculture, Forestry and Other Land Use (AFOLU). In: Climate Change 2014: Mitigation of Climate Change. Contribution of Working Group III to the Fifth Assessment Report of the Intergovernmental Panel on Climate Change [Edenhofer, O., R.Pichs-Madruga, Y. Sokona, E. Farahani, S. Kadner, K. Seyboth, A. Adler, I. Baum, S. Brunner, P. Eickemeier, B. Kriemann, J.Savolainen, S. Schlomer, C. von Stechow, T. Zwickel and J.C. Minx (eds.)]. (pp. 811-922), Cambridge University Press, Cambridge, United Kingdom and New York, NY, USA.

Watkiss, P., Hunt, A., Blyth, W., \& Dyszynski, J. (2015). The Use of New Economic Decision Support Tools for Adaptation Assessment: A Review of Methods and Applications, Towards Guidance on Applicability. Climatic Change, 132(3), 401-416. Williges, K., Mechler, R., Bowyer, P., \& Balkovic., J. (2017). Towards an assessment of adaptive capacity of the European agricultural sector to droughts. Climate Services, 7, 47-63. 